\title{
Diferenciação de bactérias do gênero Pseudomonas patogênicas ao cafeeiro por técnicas serológicas
}

\author{
Differentiation of bacteria of the genus Pseudomonas pathogenic \\ to coffee by serological techniques
}

\author{
Luis Otavio Saggion Beriam ${ }^{\text {* }}$, Flavia Rodrigues Alves Patrício', Karen Wolf Maciel ${ }^{1}$, \\ Lucas Mateus Rivero Rodrigues ${ }^{1}$, Irene Maria Gatti de Almeida ${ }^{\dagger}$
}

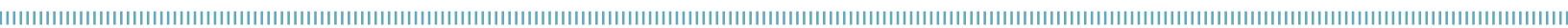

RESUMO: Há várias bactérias que causam problemas para o cafeeiro, incluindo Pseudomonas cichorii, P. syringae pv. garcae, P. syringae pv. tabaci, Burkholderia andropogonis e Xylella fastidiosa, todas elas já descritas no Brasil. Tentativas de diferenciar essas bactérias por testes serológicos de dupla difusão em ágar (dda), com antissoros produzidos contra células íntegras de $P$. s. pv. garcae, mostraram reações cruzadas, principalmente entre P. s. pv. garcae e P. s. pv. tabaci. Dessa forma, foram produzidos antissoros contra P. s. pv. garcae (linhagem patotipo IBSBF-248 - Coleção de Culturas de Fitobactérias do Instituto Biológico — IBSBF), obtidos por meio de imunizaçóes de coelhos com antígenos de proteínas do complexo proteico da membrana (CPM). Esses antissoros foram testados por dupla difusão em agarose (dda) contra diversas formas de antígenos extraídos de $P$. cichorii, $P$. s. pv. garcae e $P$. s. pv. tabaci [células autoclavadas, células tratadas com formol, exopolissacarídeos (EPS), glicoproteínas (GP) da cápsula bacteriana, proteínas de membrana e suspensão bacteriana (SB) em $\mathrm{NaCl}$ 0,85\%]. Os resultados mostraram que, dependendo do antígeno e do meio suporte da dupla difusão (com ou sem $\mathrm{MgCl}_{2}$ e/ou azul de tripano), os antissoros reagem somente com P. s. pv. garcae. Desse modo, esses antígenos podem ser usados para a rápida diagnose da mancha aureolada do cafeeiro nos testes de dda.

PALAVRAS-CHAVE: mancha aureolada; Pseudomonas syringae pv. garcae; serologia.

\begin{abstract}
Some bacterial diseases have been described causing problems in coffee, whose causal agents are Pseudomonas cichorii, P. syringae pv. garcae, P. s. pv. tabaci and Burkholderia andropogonis, all of them also occurring in Brazil. Attempts to differentiate these bacteria by double diffusion agar (dda) technique with antisera produced against whole cells of $P$. $s$. pv. garcae showed cross-reactions, especially among $P$. $s$. pv. garcae and $P$. s. $p v$. tabaci. Thus, antisera were produced against P. s. pv. garcae (pathotype strain IBSBF-248 - Phytobacteria Culture Collection of Instituto Biológico - IBSBF), using rabbit immunizations with antigens of the protein complex of membranes. These antisera were tested against different kind of antigens (autoclaved cells, cells treated with formaldehyde, capsule polysaccharides, glycoproteins, bacterial membrane proteins and bacterial suspension in $0.85 \% \mathrm{NaCl}$ ) extracted from $P$. cichorii, $P$. s. pv. garcae and $P$. s. pv. tabaci. The results showed that depending on the kind of antigen and the medium used in the double diffusion test (with or without $\mathrm{MgCl}_{2}$ and/or trypan blue), the antiserum reacted only with $P$. s. pv. garcae. Thus, these antigens may be used as an auxiliary tool in the rapid diagnosis of bacterial halo blight of coffee in the double diffusion test.
\end{abstract}

KEYWORDS: bacterial leaf blight; Pseudomonas syringae pv. garcae; serology. 


\section{INTRODUÇÃO}

Existem descritas na literatura várias bactérias que causam problemas em cafeeiro (Coffea arabica L. e C. canephora Pierre ex A. Froehner) e que já foram assinaladas no Brasil, incluindo Burkholderia andropogonis, P. syringae pv. garcae, P. s. pv. tabaci, Pseudomonas cichorii e Xylella fastidiosa (MALAVOLTA et al., 2008; BERIAM et al., 2016). Entre elas, P. syringae pv. garcae é a que atualmente vem sendo detectada em maior número, causando os principais prejuízos à cultura (ALMEIDA et al., 2013). Essa bactéria é o agente causal da "mancha aureolada do cafeeiro", descrita em nosso país em 1956 (AMARAL et al., 1956). Entre os sintomas originados pelo patógeno, os principais e característicos da doença consistem em manchas necróticas nas folhas, circundadas por halos cloróticos. Esses sintomas também podem ser ocasionados por outros patógenos do cafeeiro, como fungos e outras fitobactérias, entre elas P. cichorii, causadora do "crestamento bacteriano das folhas" (ROBBS et al., 1974), B. andropogonis, agente causal da "mancha escura bacteriana" (RODRIGUES NETO et al., 1981), e $P$. s. pv. tabaci, responsável pelo surgimento da "mancha bacteriana" (DESTÉFANO et al., 2010).

Das bactérias citadas, a diferenciação das espécies, e especialmente de patovares de Pseudomonas, nem sempre é simples e não deve ser baseada na sintomatologia apresentada pelo cafeeiro. A melhor forma de diferenciá-las é pelo isolamento em meios de cultura, testes de patogenicidade e alguns testes bioquímicos e fisiológicos, como o LOPAT e a utilização de L-trigoneline, L (+) tartarato e lactato, bem como a produção de pectato liase. Esses quatro últimos testes permitem diferenciar os patovares garcae e tabaci de $P$. syringae (YOUNG; TRIGGS, 1994). Os testes bioquímicos apresentam um fator limitante, demandando ca. de 30 dias para a obtençáo dos resultados, além de não serem exequíveis para um grande número de amostras. Uma das alternativas para diferenciar essas espécies/patovares são os testes serológicos, mediante a produção de antissoros específicos.

Pelo exposto, o objetivo deste trabalho foi determinar um método serológico eficaz para a diferenciação de isolados de Pseudomonas patogênicas ao cafeeiro, com antissoros produzidos por intermédio de células bacterianas íntegras e também do chamado "complexo proteico da membrana (CPM)", por meio da técnica de dda, em diferentes meios para a dupla difusão.

\section{MATERIAIS E MÉTODOS}

\section{Linhagens bacterianas}

As linhagens bacterianas utilizadas neste trabalho (Tabela 1) pertencem à Coleção de Culturas de Fitobactérias do Instituto Biológico (IBSBF)e estáo conservadas sob liofilização e/ou ultracongelamento $\left(-80^{\circ} \mathrm{C}\right)$. Todas as linhagens foram recuperadas em meio de cultura nutriente ágar (NA) e mantidas em estufa bacteriológica por 48 horas a $28^{\circ} \mathrm{C}$. Durante o desenvolvimento do estudo, as linhagens foram preservadas em suspensấo em água destilada esterilizada.

\section{Preparo de antígenos}

Para o preparo das diferentes formas de antígeno, as linhagens bacterianas foram cultivadas em placas de Petri com meio NA,

Tabela 1. Linhagens de Pseudomonas syringae pv. garcae da Coleção de Culturas de Fitobactérias do Instituto Biológico.

\begin{tabular}{|c|c|c|c|c|}
\hline \multirow{2}{*}{$\begin{array}{l}\text { Nolinhagem } \\
\text { IBSBF }\end{array}$} & \multicolumn{3}{|c|}{ Origem } & \multirow{2}{*}{$\begin{array}{l}\text { Ano de } \\
\text { isolamento }\end{array}$} \\
\hline & Cidade & Estado & País & \\
\hline 65 & Jaú & SP & Brasil & 1976 \\
\hline 75 & Pirajú & SP & Brasil & 1978 \\
\hline 152 & Ouro Fino & MG & Brasil & 1978 \\
\hline 158 & Campinas & SP & Brasil & 1978 \\
\hline $248^{P}$ & Garça & SP & Brasil & 1958 \\
\hline 249 & & & Quênia & 1962 \\
\hline 1.293 & Guaxupé & MG & Brasil & 1997 \\
\hline 1.372 & Cristais Paulista & SP & Brasil & 1998 \\
\hline 1.373 & $\begin{array}{l}\text { São João da } \\
\text { Boa Vista }\end{array}$ & SP & Brasil & 1998 \\
\hline 1.664 & Serra Negra & $\mathrm{SP}$ & Brasil & 2001 \\
\hline 2.212 & Franca & SP & Brasil & 2005 \\
\hline 2.511 & Patrocínio & MG & Brasil & 2007 \\
\hline 2.840 & Caconde & SP & Brasil & 2009 \\
\hline 2.841 & Águas da Prata & SP & Brasil & 2009 \\
\hline 2.883 & & & Quênia & 1973 \\
\hline 2.996 & $\begin{array}{c}\text { Monte Santo de } \\
\text { Minas }\end{array}$ & MG & Brasil & 2008 \\
\hline 2.998 & Carmo de Minas & MG & Brasil & 2008 \\
\hline 2.999 & Serra Negra & SP & Brasil & 2008 \\
\hline 3.005 & Altinópolis & $\mathrm{SP}$ & Brasil & 2008 \\
\hline 3.015 & Garça & $\mathrm{SP}$ & Brasil & 2008 \\
\hline 3.019 & $\begin{array}{l}\text { São Sebastião } \\
\text { da Grama }\end{array}$ & $\mathrm{SP}$ & Brasil & 2009 \\
\hline 3.022 & $\begin{array}{l}\text { Bragança } \\
\text { Paulista }\end{array}$ & SP & Brasil & 2009 \\
\hline 3.024 & Serra do Salitre & MG & Brasil & 2011 \\
\hline 3.031 & Varginha & MG & Brasil & 2009 \\
\hline 3.032 & Albertina & $\mathrm{SP}$ & Brasil & 2009 \\
\hline 3.037 & & & Quênia & 1972 \\
\hline 3.046 & Divinolândia & SP & Brasil & 2009 \\
\hline 3.049 & Andradas & MG & Brasil & 2009 \\
\hline 3.065 & Unaí & MG & Brasil & 2010 \\
\hline
\end{tabular}

PLinhagem patotipo. 
por 48 horas a $28^{\circ} \mathrm{C}$, e os respectivos antígenos, armazenados em congelador, a $-20^{\circ} \mathrm{C}$.

Foram utilizadas seis formas diferentes de antígenos:

- Suspensão bacteriana (SB), em solução salina esterilizada $(\mathrm{NaCl} 0,85 \%)$;

- Antígenos autoclavados por 120 minutos a $121^{\circ} \mathrm{C}$, obtidos por meio de uma SB;

- Antígenos tratados pelo formol, obtidos por intermédio da SB em solução salina, tratada com o mesmo volume de salina formalizada $(\mathrm{NaCl} 0,85 \%+0,6 \%$ de formol). As suspensóes foram mantidas por 48 horas em temperatura ambiente, centrifugadas $(10.000 \mathrm{~g} / 10 \mathrm{~min})$, com os precipitados ressuspendidos em salina formalizada a $0,3 \%$ de formol;

- Fração de exopolissacarídeos (EPS), extraída do crescimento bacteriano ressuspendido em tampão fosfato salino (PBS). Essas suspensōes foram homogeneizadas em vórtex, em temperatura ambiente, por $1 \mathrm{~min}$ e, em seguida, centrifugadas (12.000 g/60 min). Os precipitados foram descartados e os sobrenadantes tratados com quatro volumes de acetona a $-20^{\circ} \mathrm{C}$, armazenados por 12 horas a $8^{\circ} \mathrm{C}$, sendo em seguida centrifugadas $(12.000 \mathrm{~g} / 60 \mathrm{~min}$ ). Os sobrenadantes foram descartados, e os precipitados ressuspendidos em água destilada esterilizada. Para as quatro diferentes formas de antígenos descritas, foi utilizada a proporção de 30 $\mathrm{mg}$ de peso fresco do crescimento bacteriano para 1.000 $\mu \mathrm{L}$ dos respectivos diluentes (solução salina, tampão fosfato de sódio, salina formalizada), de acordo com a metodologia de DE BOER; SCHAAD (1990);

- CPM, extraído de acordo com a metodologia descrita por THAVEECHAI; SCHAAD (1986). O crescimento bacteriano em meio NA foi coletado com alça de Drigalski em uma solução de cloreto de lítio ( $\mathrm{LiCl}) 0,2 \mathrm{M}$, e a suspensão resultante foi mantida sob agitação de $250 \mathrm{rpm}$, ao longo de 3 horas, a $45^{\circ} \mathrm{C}$. A suspensão foi centrifugada a $12.000 \mathrm{~g}$, por $15 \mathrm{~min}, \mathrm{a} 4^{\circ} \mathrm{C}$, descartando os precipitados, e os sobrenadantes foram novamente centrifugados a $30.000 \mathrm{~g}$, por 30 minutos, a $4^{\circ} \mathrm{C}$. Os precipitados foram descartados, e os sobrenadantes, centrifugados a 100.000 g por 2 horas a $4^{\circ} \mathrm{C}$. Os precipitados foram ressuspendidos em 1/100 do volume original, em água destilada esterilizada, constituindo a fração do CPM, armazenada a $-20^{\circ} \mathrm{C}$;

- Fração glicoproteica, extraída de acordo com DIGAT; CAMBRA (1976). As glicoproteínas (GP) foram extraídas da seguinte forma: o crescimento bacteriano foi coletado com alça de Drigalski em água destilada e mantido sob agitação de $250 \mathrm{rpm} / 180 \mathrm{~min}$ por 2 horas. Em seguida, a suspensão foi centrifugada por $15 \mathrm{~min} / 5.000$ $\mathrm{g}$, a $4^{\circ} \mathrm{C}$, descartando os precipitados, e os sobrenadantes foram novamente centrifugados $\left(15 \mathrm{~min} / 10.000 \mathrm{~g} / 4^{\circ} \mathrm{C}\right)$. Os sobrenadantes resultantes dessa última centrifugação foram tratados com solução saturada de sulfato de amônio $\left[\left(\mathrm{NH}_{4}\right)_{2} \mathrm{SO}_{4}(\mathrm{v} / \mathrm{v})\right]$. Esse material foi mantido em temperatura de $8^{\circ} \mathrm{C}$ por 16 horas e posteriormente centrifugado por $45 \mathrm{~min} / 15.000 \mathrm{~g} / 4^{\circ} \mathrm{C}$. Os sobrenadantes foram descartados, e os precipitados, ressuspendidos em 1/100 do volume original em água destilada e submetidos à diálise contra água destilada, para extraçáo do $\left(\mathrm{NH}_{4}\right)_{2} \mathrm{SO}_{4}$.

\section{Produção de antissoros e testes serológicos}

Para obtençáo dos antissoros, a linhagem patotipo de $P$. s. pv. garcae (IBSBF $248^{\mathrm{P}}$ ) foi cultivada em meio NA, por 48 horas, a $28^{\circ} \mathrm{C}$. Em seguida, as colônias obtidas foram coletadas e ressuspendidas em tampão fosfato salino $0,01 \mathrm{M}, \mathrm{pH} 7$ (ca. $10^{9}$ UFC. $\mathrm{mL}^{-1} /$ escala de McFarland) e lavadas três vezes nesse mesmo tampão, por centrifugação ( $10.000 \mathrm{~g} / 3 \mathrm{~min})$. O precipitado final foi ressuspendido em $200 \mu \mathrm{L}$ de PBS, com adição de $200 \mu \mathrm{L}$ de adjuvante completo de Freund. Essas suspensões foram utilizadas para imunização de coelhos da raça Nova Zelândia, com peso aproximado de $2,5 \mathrm{~kg}$. Antes das imunizaçôes, os animais foram submetidos ao processo de sangria para obtenção dos soros normais, utilizados como controle negativo das reaçôes serológicas. Os animais foram imunizados via linfonódulo (OLIVEIRA, 1975), com duas injeçôes de antígenos emulsificados com igual volume de adjuvante completo de Freund, com intervalos de 15 dias entre as imunizaçóes, com sangrias semanais. Além dos antissoros produzidos contra célula total, também foram produzidos antissoros contra o CPM (linhagem IBSBF 248), segundo metodologia descrita. Os procedimentos para a produção de antissoros foram aprovados pela Comissão de Ética em Experimentação Animal do Instituto Biológico (Protocolo no 116/11).

Foi realizado previamente teste de dda para a determinaçáo da melhor concentração do antígeno e antissoro para os testes serológicos, utilizando-se os antígenos nas concentraçóes de 7,5, 15, 30 e $60 \mathrm{mg} \cdot \mathrm{mL}^{-1}$ de peso fresco do crescimento bacteriano em NA ( 48 horas a $28^{\circ} \mathrm{C}$ ), suspendidos em solução salina esterilizada.

O relacionamento serológico entre as diversas linhagens bacterianas previamente selecionadas (Tabela 1) foi efetuado com teste de dda, com os seguintes meios:

- Agarose a $1 \%$, contendo $0,02 \%$ de azida de sódio;

- Agarose a $1 \%$, contendo $0,02 \%$ de azida de sódio, $2 \%$ de cloreto de magnésio e $0,5 \mathrm{~mL}$ de uma solução de azul tripano a $1 \%$;

- Agarose a $1 \%$, contendo $0,02 \%$ de azida de sódio e $2 \%$ de cloreto de magnésio;

- Agarose a $1 \%$, contendo $0,02 \%$ de azida de sódio e $0,5 \mathrm{~mL}$ de uma solução de azul tripano a $1 \%$.

Em todos os casos, a agarose foi dissolvida em solução salina. Os testes serológicos foram conduzidos segundo protocolos previamente determinados (BERIAM et al., 1998).

Os antissoros produzidos contra P. syringae pv. garcae também foram testados por dda para outras fitobactérias patogênicas 
ao cafeeiro, relacionadas na Tabela 2, utilizando-se as mesmas formas de antígenos (SB, SB autoclavada, GP, CPM, antígenos tratados com formol e EPS).

\section{RESULTADOS E DISCUSSÃO}

Os resultados dos testes de dda das 28 linhagens de $P$. s. pv. garcae e das demais bactérias patogênicas ao cafeeiro (B. andropogonis, P. cichorii e P.s. pv. tabaci) contra os antissoros produzidos contra células totais (AS-248-144) e contra o CPM (AS-248-145) podem ser visualizados nas Tabelas 3 e 4.

No teste para a determinação da concentração ótima do antígeno e do antissoro, o antissoro sem diluição apresentou os melhores resultados. Já para os antígenos, a SB na concentraçáo de $30 \mathrm{mg} \cdot \mathrm{mL}^{-1}$ se mostrou mais eficiente. SUGIMORI et al. (1978) já haviam obtido antissoro para P. s. pv. garcae com o uso da mesma técnica, porém este estudo foi mais amplo, porque incluiu um número maior de isolados e diferentes formas de antígenos. Para estudos com outros patossistemas, também foram desenvolvidos antissoros para fins de diagnose de fitobactérias (SILVEIRA et al., 2002).

A análise da Tabela 3 evidencia que tanto os antígenos na forma de SB como os do CPM são os mais indicados para trabalhos objetivando a diagnose de $P$. syringae pv. garcae, uma vez que os antissoros produzidos contra células totais reconheceram todas as 28 linhagens de P. syringae pv. garcae testadas. Essas duas formas de antígenos já foram apontadas como as mais indicadas para experimentos visando à diagnose de outras fitobacterioses, como Xanthomonas axonopodis pv. passiflorae, agente causal da "mancha oleosa" do maracujazeiro (BERIAM et al., 1998). As grandes vantagens da utilização de antígenos na forma de SB consistem na rapidez e na facilidade de sua obtenção.

Foram desenvolvidos alguns experimentos utilizando macerados de plantas de cafeeiro infectadas artificialmente com P. s. pv. garcae extraídos em tampáo fosfato $0,01 \mathrm{M}, \mathrm{pH} 7$. $\mathrm{Na}$ dependência da quantidade de células bacterianas presentes na área lesionada, também foi possível, em alguns casos, a detecçáo de $P$. s. pv. garcae diretamente do material vegetal. Esses experimentos deveráo ser repetidos com um maior número de amostras. Há ainda a alternativa de se proceder a um incremento no número de células bacterianas, por meio do crescimento bacteriano em meio líquido proveniente de pequenas porçôes de tecido vegetal com sintomas colocadas nesse meio, e utilizar esse material como antígeno reagente nos testes de dda.

Embora os antígenos na forma de CPM e GP tenham reagido positivamente com praticamente todas as linhagens testadas (Tabela 3), esses antígenos não são os mais indicados para fins de diagnose, por demandarem um tempo maior para extração (mínimo de dez dias), enquanto os antígenos na forma de SB são obtidos do crescimento bacteriano em um período de 72 a 96 horas. Uma alternativa é produzir, além de antissoros contra o CPM, também antissoros contra a fração glicoproteína. Em ambos os casos, os antígenos imunizantes são mais específicos, o que, provavelmente, possibilita a diminuição ou mesmo a eliminação das reaçôes cruzadas, principalmente entre linhagens pertencentes a diferentes espécies.

As demais formas de antígeno (formol, EPS e material autoclavado) não são indicadas para trabalhos visando à diagnose, uma vez que o número de linhagens reconhecidas foi baixo - 35,7\% para o formol, 78,6\% para EPS e 32,1\% para os antígenos autoclavados. Dessa forma, é possível a ocorrência de resultados não confiáveis (tanto falsos negativos como falsos positivos). Tais formas de antígenos podem apresentar algum interesse no desenvolvimento de trabalhos com vistas ao estudo de eventuais serotipos ou variantes serológicas de P. s. pv. garcae, a exemplo do que acontece com outras fitobactérias (OTTA; ENGLISH, 1971). Os estudos relacionados a eventuais serotipos devem envolver um número maior de isolados. Com o número de linhagens testadas no presente trabalho, não foi possível afirmar que as diferentes reaçôes serológicas ocorridas são decorrentes da presença de serotipos.

Os antígenos na forma de EPS só apresentaram reações positivas com algumas linhagens de P. s. pv. garcae (Tabela 3 ), sendo um indicativo de que essa forma de antígeno talvez pudesse ser utilizada na diferenciação de eventuais serotipos de $P$. s. pv. garcae. A desvantagem dessa forma de antígeno é não apresentar reação positiva com todas as linhagens de P. s. pv. garcae testadas. Em trabalho de triagem em campo podem ocorrer

Tabela 2. Linhagens de bactérias fitopatogênicas que causam sintomas de manchas foliares em cafeeiros.

\begin{tabular}{|c|c|c|c|c|}
\hline No da linhagem IBSBF & Patógeno bacteriano & Hospedeiro & Origem & Ano de isolamento \\
\hline 166 & Burkholderia andropogonis & Coffea arabica & Brasil & 1979 \\
\hline $199^{\top}$ & Burkholderia andropogonis & Sorghum bicolor & Estados Unidos & 1959 \\
\hline 587 & Pseudomonas cichorii & Coffea arabica & Brasil & 1973 \\
\hline $1.784^{\top}$ & Pseudomonas cichorii & Cichorium endivia & Alemanha & 1929 \\
\hline $1.972^{P}$ & Pseudomonas syringae pv. tabaci & Nicotiana tabacum & Hungria & 1959 \\
\hline 2.240 & Pseudomonas syringae pv. tabaci & Coffea arabica & Brasil & 2005 \\
\hline 2.241 & Pseudomonas syringae pv. tabaci & Coffea arabica & Brasil & 2005 \\
\hline 2.249 & Pseudomonas syringae pv. tabaci & Coffea arabica & Brasil & 2005 \\
\hline
\end{tabular}

IBSBF: Coleção de Culturas de Fitobactérias do Instituto Biológico; 'Tinhagem tipo; PLinhagem patotipo. 
Tabela 3. Testes serológicos entre os antissoros produzidos contra células totais (As-248-114) e contra proteínas de membrana (As-248-1 15) de P. s. pv. garcae.

\begin{tabular}{|c|c|c|c|c|c|c|c|c|c|c|c|c|}
\hline \multirow{4}{*}{$\begin{array}{l}\text { Linhagens } \\
\text { IBSBF }\end{array}$} & \multicolumn{12}{|c|}{ Antígenos/Antissoros } \\
\hline & \multicolumn{2}{|c|}{ Suspensão } & \multicolumn{2}{|c|}{ Formol } & \multicolumn{2}{|c|}{ CPM } & \multicolumn{2}{|c|}{ EPS } & \multicolumn{2}{|c|}{ GP } & \multicolumn{2}{|c|}{ AUTO } \\
\hline & 248 & 248 & 248 & 248 & 248 & 248 & 248 & 248 & 248 & 248 & 248 & 248 \\
\hline & 144 & 145 & 144 & 145 & 144 & 145 & 144 & 145 & $144 / 7$ & $145 / 7$ & 144 & 145 \\
\hline 65 & ++ & - & - & - & + & + & - & - & ++ & + & + & - \\
\hline 75 & + & + & - & - & + & + & + & - & ++ & + & - & - \\
\hline 152 & ++ & + & - & - & + & + & - & - & - & - & + & - \\
\hline 158 & +++ & ++ & - & + & +++ & +++ & + & + & +++ & ++ & + & + \\
\hline 248 & + & ++ & - & - & + & + & - & + & + & + & + & + \\
\hline 249 & + & + & + & + & ++ & - & - & + & - & + & - & - \\
\hline 1.293 & ++ & + & - & - & + & + & - & + & + & + & + & - \\
\hline 1.372 & ++ & ++ & + & + & ++ & $+{ }^{*}$ & - & + & + & + & + & + \\
\hline 1.373 & ++ & + & - & - & ++ & ++ & + & + & + & + & & - \\
\hline 1.664 & +++ & + & - & + & + & ++ & - & - & + & + & ND & \\
\hline 2.212 & ++ & & + & + & ++ & ++ & + & + & - & + & + & - \\
\hline 2.511 & +++ & + & - & $(+)$ & + & + & + & + & ++ & + & + & - \\
\hline 2.840 & +++ & ++ & - & - & ++ & + & - & - & + & + & & - \\
\hline 2.841 & +++ & ++ & - & - & + & + & + & + & + & + & $?$ & $?$ \\
\hline 2.883 & +++ & + & - & - & + & + & + & + & ND & ND & ND & ND \\
\hline 2.996 & +++ & + & + & + & ++ & + & + & + & + & + & $?$ & $?$ \\
\hline 2.999 & ++ & + & - & - & ++ & + & - & - & + & + & - & - \\
\hline 3.005 & + & ++ & + & + & ++ & + & + & + & + & + & - & - \\
\hline 3.015 & +++ & ++ & + & + & + & + & + & + & + & + & - & - \\
\hline 3.019 & + & ++ & - & - & ++ & + & - & - & ++ & + & - & - \\
\hline 3.022 & ++ & + & - & - & ++ & ++ & + & + & $?$ & $?$ & - & - \\
\hline 3.024 & ++ & + & - & - & +++ & ++ & + & + & + & + & - & - \\
\hline 3.031 & ++ & + & - & - & + & ++ & + & + & + & + & - & - \\
\hline 3.032 & ND & ND & - & - & ++ & ND & + & $+d$ & ND & ND & ND & ND \\
\hline 3.037 & +++ & + & - & - & +++ & ++ & + & + & $?$ & $?$ & $?$ & $?$ \\
\hline 3.046 & +++ & + & - & - & ++ & ++ & + & $(+)$ & + & + & - & - \\
\hline 3.049 & +++ & ++ & - & - & ++ & ++ & $(+)$ & + & ++ & $(+)$ & + & - \\
\hline 3.065 & +++ & ++ & + & + & + & + & + & + & + & + & - & - \\
\hline
\end{tabular}

IBSBF: Coleção de Culturas de Fitobactérias do Instituto Biológico; ND: não determinado; ?: resultado duvidoso; CPM: complexo proteico da membrana; EPS: exopolissacarídeos; GP: glicoproteínas; AUTO: autoclavado.

Tabela 4. Relacionamento serológico entre linhagens de bactérias patogênicas ao cafeeiro.

\begin{tabular}{|c|c|c|c|c|c|c|c|c|c|c|c|c|}
\hline \multirow{4}{*}{ IBSBF } & \multicolumn{12}{|c|}{ Antígenos/Antissoros } \\
\hline & \multicolumn{2}{|c|}{ Suspensão } & \multicolumn{2}{|c|}{ Formol } & \multicolumn{2}{|c|}{ CPM } & \multicolumn{2}{|c|}{ EPS } & \multicolumn{2}{|c|}{ GP } & \multicolumn{2}{|c|}{ AUTO } \\
\hline & $248^{*}$ & 248 & 248 & 248 & 248 & 248 & 248 & 248 & 248 & 248 & 248 & 248 \\
\hline & 144 & 145 & 144 & 145 & 144 & 145 & 144 & 145 & 144 & 145 & 144 & 145 \\
\hline 166 & ++ & + & - & - & + & $+*$ & - & - & - & - & - & - \\
\hline 199 & ++ & - & - & - & + & - & - & - & - & - & - & - \\
\hline 587 & ++ & + & - & - & + & - & - & - & + & + & - & + \\
\hline 1.784 & + & - & - & - & - & - & - & - & - & - & - & - \\
\hline 1.972 & ++ & - & - & - & - & - & + & - & - & - & - & - \\
\hline 2.240 & +++ & + & - & - & - & - & + & + & - & - & - & - \\
\hline 2.241 & ++ & - & - & - & + & - & - & - & - & - & - & - \\
\hline 2.249 & +++ & + & - & - & + & - & - & - & - & + & - & - \\
\hline 2.996 & +++ & ++ & - & + & ++ & + & & & $?$ & + & + & + \\
\hline
\end{tabular}

IBSBF: Coleção de Culturas de Fitobactérias do Instituto Biológico; *antissoros; CPM: complexo proteico da membrana; EPS: exopolissacarídeos; GP: glicoproteínas; AUTO: autoclavado. 
escapes dos resultados, com falsos negativos. Mais uma vez, seria interessante testar um número maior de linhagens bacterianas.

O relacionamento serológico entre os antissoros produzidos contra células totais (AS-248-144) e o CPM com as demais bactérias patogênicas ao cafeeiro (B. andropogonis (ISBBF-166 e IBSBF-199), $P$. cichorii (IBSBF-587 e IBSBF-1784) e $P$. s. pv. tabaci (IBSBF-2240, IBSBF-2241 e IBSBF-2249) (Tabela 4) mostraram que, quando as SBs são empregadas como antígenos e se utiliza como meio de reação agarose em solução salina e azida de sódio, há reaçóes cruzadas entre os antissoros contra célula total e os antígenos de todas as linhagens, o que inviabiliza a adoção desse teste para esse meio de reação. Com relação aos antissoros para células totais, reaçóes cruzadas entre $P$. s. pv. garcae e $P$. s. pv. tabaci já eram esperadas, visto se tratarem de patovares de uma mesma espécie bacteriana, que apresentam uma série de determinantes antigênicos comuns, responsáveis pelas reaçôes cruzadas.

A utilização de diferentes meios suportes para as reaçóes de dupla difusão está sumarizada na Tabela 5. Os meios 2 e 4 contendo, além de agarose, $\mathrm{NaCl} \mathrm{e} \mathrm{NaN}_{3}, \mathrm{MgCl}_{2} \%$ + azul de tripano (solução a 0,1\% em água) em $100 \mathrm{~mL}$ de meio básico e azul de tripano (solução a 0,1\% em água) em $100 \mathrm{~mL}$ de meio básico, respectivamente, foram os mais específicos quando testados com as diferentes formas de antígenos contra os antissoros produzidos com base no CPM. A combinação entre o antissoro produzido contra proteínas de membrana e o meio 4 de dupla difusão foi a mais específica. Só houve uma reação cruzada entre AS-248145 e uma linhagem de B. andropogonis (Tabela 5). Essa reação só ocorreu com uma das linhagens testadas de B. andropogonis, mas náo impede que esse antissoro seja utilizado para a separação dos dois isolados de P. syringae patogênicos ao cafeeiro — garcae e tabaci, que são os mais difíceis de serem separados por outros testes comumente utilizados na identificação de fitobactérias. Além disso, morfologicamente, B. andropogonis e P. s. pv. garcae são completamente diferentes e separadas com relativa facilidade.

Dessa maneira, de acordo com os resultados obtidos, a combinação de antígenos na forma de SB com o meio suporte contendo azul de tripano poderá ser empregada para diagnose da mancha aureolada do cafeeiro.

Tabela 5. Relacionamento serológico entre antissoros contra Pseudomonas syringae pv. garcae e demais bactérias patogênicas ao cafeeiro em diferentes meios de dupla difusão.

\begin{tabular}{|c|c|c|c|c|c|c|c|c|c|}
\hline & & \multicolumn{2}{|c|}{ Meio $1^{1}$} & \multicolumn{2}{|c|}{ Meio 2} & \multicolumn{2}{|c|}{ Meio 3} & \multicolumn{2}{|c|}{ Meio 4} \\
\hline & & $\begin{array}{c}\text { AS- } 248^{2} \\
144\end{array}$ & $\begin{array}{c}\text { AS- } 248^{3} \\
145\end{array}$ & $\begin{array}{c}\text { AS-248 } \\
144\end{array}$ & $\begin{array}{c}\text { AS- } 248 \\
145\end{array}$ & $\begin{array}{c}\text { AS-248 } \\
144\end{array}$ & $\begin{array}{c}\text { AS-248 } \\
145\end{array}$ & $\begin{array}{c}\text { AS-248 } \\
144\end{array}$ & $\begin{array}{c}\text { AS- } 248 \\
145\end{array}$ \\
\hline \multirow{3}{*}{166} & SUSP. ${ }^{4}$ & - & - & - & - & - & - & + & - \\
\hline & GP & - & - & - & - & - & - & - & - \\
\hline & CPM & + & - & + & - & + & $(+)$ & + & - \\
\hline \multirow{3}{*}{199} & SUSP. & - & - & - & - & - & - & - & - \\
\hline & GP & + & - & - & - & - & - & - & - \\
\hline & CPM & + & + & + & - & + & + & + & + \\
\hline \multirow{3}{*}{2.240} & SUSP. & - & - & + & - & - & - & + & - \\
\hline & GP & - & - & - & - & - & - & - & - \\
\hline & CPM & + & - & + & - & - & - & - & - \\
\hline \multirow{3}{*}{2.241} & SUSP. & + & + & - & - & - & - & - & - \\
\hline & GP & + & - & + & - & + & - & + & - \\
\hline & CPM & + & - & + & - & + & - & + & - \\
\hline \multirow{3}{*}{2.249} & SUSP. & + & - & + & - & + & - & + & - \\
\hline & GP & + & - & + & - & + & - & + & - \\
\hline & CPM & + & - & + & - & + & - & + & - \\
\hline \multirow{3}{*}{1.784} & SUSP. & - & - & - & - & - & - & - & - \\
\hline & GP & - & - & - & - & - & - & - & - \\
\hline & CPM & - & - & - & - & - & - & - & - \\
\hline \multirow{3}{*}{1.972} & SUSP. & + & - & - & - & - & - & + & - \\
\hline & GP & + & - & - & - & + & - & + & - \\
\hline & CPM & + & - & + & - & + & - & + & - \\
\hline \multirow{3}{*}{3.005} & SUSP. & + & + & + & + & + & + & + & + \\
\hline & GP & + & + & + & + & + & + & + & + \\
\hline & CPM & + & + & + & + & + & + & + & + \\
\hline
\end{tabular}

'Meio 1 - agarose $1 \%+\mathrm{NaCl} 0,85 \%+\mathrm{NaN}_{3} 0,02 \%$; Meio 2 - agarose $1 \%+\mathrm{NaCl} 0,85 \%+\mathrm{NaN}_{3} 0,02 \%+\mathrm{MgCl}_{2} 2 \%+$ azul de tripano (solução a $0,1 \%$ em áqua) ( $1 \mathrm{~mL}$. $\left.100 \mathrm{~mL}^{-1}\right)$; Meio 3 - agarose $1 \%+\mathrm{NaCl} 0,85 \%+\mathrm{NaN}_{3} 0,02 \%+\mathrm{MgCl}_{2} \%$; Meio 4 - agarose $1 \%+\mathrm{NaCl} 0,85 \%+\mathrm{NaN}$ $0,02 \%$ + azul de tripano (solução a $0,1 \%$ em áqua) $\left(1 \mathrm{~mL}\right.$. $\left.100 \mathrm{~mL}^{-1}\right)$; ${ }^{2}$ antissoro contra célula total; ${ }^{3}$ antissoro contra complexo proteico da membrana; ${ }^{4}$ formas de antígenos: suspensão bacteriana (SUSP); glicoproteínas (GP); complexo proteico da membrana (CPM). 
Convém salientar que os maiores problemas com reaçóes cruzadas ocorrem entre P. s. pv. garcae, P. s. pv. tabaci e P. cichorii. Morfologicamente, $P$. s. pv. garcae e $B$. andropogonis são facilmente diferenciáveis em meio de cultura, além do fato de $B$. andropogonis não ser fluorescente sob luz ultravioleta quando cultivada em meio B de King, enquanto $P$. s. pv. garcae o é. O mesmo não ocorre para $P$. s. pv. garcae, $P$. $s$. pv. tabaci nem $P$. cichorii. Há outras características que, aliadas aos resultados dos testes serológicos, também podem auxiliar e até mesmo corroborar a identificação de $P$. s. pv. garcae. A diferenciação entre as espécies $P$. cichorii e $P$. syringae é feita com relativa facilidade pelos testes LOPAT (LELLIOTT et al., 1966).
De forma geral, $P$ s. pv. tabaci apresenta fluorescência em meio $\mathrm{B}$ de King mais pronunciada quando comparada à fluorescência de $P$. s. pv. garcae, mas essa característica não é suficiente para separar ambas. Os testes com alguns sais de ácidos orgânicos e alguns carboidratos auxiliam na separação dos isolados das duas bactérias, mas, como já comentado, demandam longo período de tempo.

Os dados obtidos com as linhagens utilizadas, quando testadas em dupla difusão com o antissoro produzido contra proteínas de membranas (AS-248-145) com o meio 4, apontam uma alternativa para a diagnose rápida e segura de P. s. pv. garcae.

| | | | | | | | | | | | | | | | | | | || | | | | | | | | | | | | | | | | | | | | | | | | | | | | | | | | | | | | | | | | | | | | | | | | | | | | | | | | | | | | | | | | | | | | | | | | | | | | | | | | | | | | | | | | | | | | | | | | | | | | | | | | | | | | | | | | | | | | | | | | | | | | | | | | | | | | | | | | | | | | | | | | | | | | | | | | | | | | | | | | | | | | | | | | | | | | | | | | | | | | | | | | | | | | | | | | REFERÊNCIAS

ALMEIDA, I.M.G.; MACIEL, K.M.; BERIAM, L.O.S.; RODRIGUES, L.M.R.; DESTÉFANO, S.A.L.; RODRIGUES NETO, J.; PATRÍCIO, F.R.A. Increase in incidence of bacterial halo blight (Pseudomonas syringae p. garcae) in coffee producing areas in Brazil. In: INTERNATIONAL CONFERENCE ON COFFEE SCIENCE, 24., San José, Costa Rica. Proceedings... v.24, p.1080-1084, 2013.

AMARAL, J.F.; TEIXEIRA, C.G.; PINHEIRO, E.D. O bactério causador da mancha aureolada do cafeeiro. Arquivos do Instituto Biológico, v.23, p.151-155, 1956.

BERIAM, L.O.S.; MALAVOLTA JÚNIOR, V.A.; ALMEIDA, I.M.G.; RODRIGUES NETO, J.; ABRAMIDES, P.G. 2016 . Bactérias fitopatogênicas no Brasil - levantamento bibliográfico. 2016. Disponível em: <http://germo.apta.sp.gov.br/fitobacterias/index. asp>. Acesso em: 04 set. 2016.

BERIAM, L.O.S.; MALAVOLTA JÚNIOR, V.A.; ROSATO, Y.B.; YANO, T. Serologia aplicada ao estudo de Xanthomonas campestris pv. passiflorae, agente causal da bacteriose do maracujazeiro. Arquivos do Instituto Biológico, v.65, n.2, p.25-33, 1998.

DE BOER, S.H.; SCHAAD, N.W. Preparation of antigen, bacteria. In: HAMPTON, R.; BALL, E.; DE BOER, S.H. Serological methods for detection and identification of viral and bacterial plant pathogens. Estados Unidos: APS Press, 1990. p.27-31.

DESTÉFANO, S.A.L.; RODRIGUES, L.M.; BERIAM, L.O.S.; PATRÍCIO, F.R.A.; THOMAZIELLO, R.A.; RODRIGUES NETO, J. Bacterial leaf spot of coffee caused by Pseudomonas syringae pv. tabaci in Brazil. Plant Pathology, v.59, p. 1162-1 163, 2010.

DIGAT, B.; CAMBRA, M. Specificity of antigens in Pseudomonas solanacearum E. F.Sm. and application of serology for studying bacterial wilt. In: INTERNATIONAL PLANNING CONFERENCE AND WORKSHOP ON THE ECOLOGY AND CONTROL OF BACTERIAL WILT CAUSED BY PSEUDOMONAS SOLANACEARUM, 1. SEQUEIRA L.; KELLMAN, A. (Eds.). Proceedings... Raleigh, North Carolina, 1976. p.18-24.

LELLIOTT, R.A.; BILLING, R.A.; HAYWARD, A.C. A determinative scheme for the fluorescent plant pathogenic pseudomonads. Journal of Applied Bacteriology, v.29, n.3, p. 470-489, 1966.
MALAVOLTA JR., V.A.; BERIAM, L.O.S.; ALMEIDA, I.M.G.; RODRIGUES NETO, J.; ROBBS, C.F. Bactérias fitopatogênicas assinaladas no Brasil: uma atualização. Summa Phytopathologica, Botucatu, v.34, supl. esp., p. 1-88, 2008.

OLIVEIRA, A.R. Considerações sobre antissoros obtidos pela técnica de injeção via linfonódulo. Summa Phytopathologica, v. 1, p.61-64, 1975 .

OTTA, J.D.; ENGLISH, H. Serology and pathology of Pseudomonas syringae. Phytopathology, v.61, p.443-452, 1971.

ROBBS, C.F.; KIMURA, O.; RIBEIRO, R.L.D.; OYADOMARI, L.C. "Crestamento bacteriano das folhas": nova enfermidade do cafeeiro (Coffea arabica L.) incitada por Pseudomonas cichorii (Swingle) Stapp. Arquivos da Universidade Federal Rural, Rio de Janeiro, v.4, n.2, p.1-5, 1974.

RODRIGUES NETO, J.; FIGUEIREDO, P.; MARIOTTO, P.R.; ROBBS, C.F. Pseudomonas andropogonis (Smith, 1911) Stapp, 1928, agente causal da "mancha escura bacteriana" em folhas de cafeeiro (Coffea arabica L.). Arquivos do Instituto Biológico, v.48, p.31-36, 1981 .

SILVEIRA, J.R.P.; CASTRO, L.A.S.; COUTO, M.E.O.; MARTINS, O.M.; BARNI, V. Produção de anti-soros para diagnose de pectobactérias causadoras de podridão mole em batata. Pesquisa Agropecuária Gaúcha, v.8, n.1, p.7-14, 2002.

SUGIMORI, M.H.; OLIVEIRA, A.R.; NAKAMURA, T.; RODRIGUES NETO, J. Anti-soro para Pseudomonas syringae pv. garcae preparados pela técnica de injeção no linfonódulo. Summa Phytopathologica, v.4, p.7, 1978.

THAVEECHAI, N.; SCHAAD, N.W. 1986. Serological and electrophoretic analysis of a membrane protein extract of Xanthomonas campestris pv. campestris from Thailand. Phytopathology, v.76, n.2, p.139-147, 1986.

YOUNG, J.M.; TRIGGS, C.M. Evaluation of determinative tests for pathovars of Pseudomonas syringae Van Hall 1902. Journal of Applied Bacteriology, v.77, p.195-207, 1994. 